\title{
Defining the information flows for DLT of a transport company in the mining industry according to the criteria for sustainable development
}

\author{
Teodora Hristova ${ }^{1, *}$, Dimitar Anastasov ${ }^{2}$, and Zdravets Evtimov ${ }^{2}$ \\ ${ }^{1}$ University of Mining and Geology "St. Ivan Rilski”, Department of Electrical Engineering, 1700 Sofia, Bulgaria \\ ${ }^{2}$ University of Mining and Geology "St. Ivan Rilski”, Department of Mining of Mineral Deposits, 1700 Sofia, Bulgaria
}

\begin{abstract}
The application of information technologies leads to the improvement of the companies' production parameters in each sector according to the criteria for sustainable development. Naturally, in order to achieve efficiency, they must be tailored to the specifics of the industry, in this case the mining industry. The article proposes a methodology for the introduction of Distributed Ledger Technology (DLT) for the transport information flow at a mining company. Based on the chosen organizational structure, the participating actors and the data they share, the information channels are determined. According to the necessary rights of the participants to modify the transactions and the number of channels of the transport information flow, a consensus mechanism Practical Byzantine Fault Tolerant and the so-called smart contract have been chosen. Different DLT platforms are analyzed. Hyperledger Fabric was selected as an appropriate platform in order to ensure the continuity of the system, the asynchronous control of the various channels and the ability to include different actors.
\end{abstract}

\section{Introduction}

In the second half of the $\mathrm{XX}^{\text {th }}$ century there is an increase in population along with global economic growth, which is associated with excessive, intensive and uncontrolled use of natural resources [1]. In order to meet the needs of present and future generations on the Earth, the Brundtland Commission published a report on the sustainable development in all areas of life and human activity [2]. This means that the implementation of measures in one area must not be at the expense of deteriorating performance in another area. In addition, the measures taken should not be temporary initiatives, but long-term management decisions that have a positive effect on all areas affected.

Dubinski defined the following main pillars of sustainable development in the mining sector [1]:

- technical and economic activities for continued economic growth;

- introduction of ecological measures for environmental protection and appropriate use of natural resources;

- social events to improve working conditions, care for employees and personal development in the mining community.

With the growth observed in the quantities of extracted minerals from ancient times to present days, the main aim of the economic and technical means is the reasonable acquisition of natural resources. Therefore, according to the first pillar of economic growth, it is recommended to undertake measures for long-term sustainability in terms of planned production and sales volumes, which is directly related to the improvement of the technical means for extraction and processing of mineral resources.

In recent years, measures have been taken worldwide to reduce harmful emissions of waste products into soil and water generated by the mining, chemical and pharmaceutical industries $[3,4]$. The reclamation of the excavated land masses and the improvement of the working conditions with reduced amounts of industrial accidents, dust and noise are considered with regard to the environmental measures [5]. The reduction of industrial accidents and occupational diseases, due to the presence of harmful substances are the main target for improving the working conditions, typical not only for the mining, but also for the chemical industry and agriculture. They have the highest share in countries with low innovation potential and in developing countries [6].

According to [7], the measures become effective with government support and this is proved by the enactment of many directives for reclamation and waste recycling [8, 9] from the mining activities, reduction of carbon emissions, efficient use of energy sources, etc.

At the same time, measures for staff training with new technologies, introduction of leisure activities, practices for the development of the innovative concept "Shared values", the "Got it" system for collection, evaluation and implementation of ideas from the employees, communication programs with the community and others are recommended $[10,11]$.

\footnotetext{
* Corresponding author: teodora@mgu.bg
} 
An essential element for achieving the recommendations for sustainable development is the life cycle assessment (LCA) for each production process. There are two aspects with regard to the mining industry [12]. On the one hand, this is the impact assessment of the products from the activity on the environment and comparison of the indicators of different types of mining per kilogram. On the other hand, the mining industry can use LCA to assess the impact of its activities on nature in order to improve the technology.

\section{Sustainable development and information technology}

The introduction and evaluation of production activities according to the criteria for sustainable development can be done through new technical means for data management and processing, related to the complexity of the links among the individual sectors in each company. The implementation of an information system would not only lead to traceability and security of information flows, but would make progress in increasing the innovation potential in the mining sector. At the current stage of production, Bulgaria is the only EU member state with the lowest innovation index [10]. Therefore, process management, assessment of the state and raising the innovation index would not be possible without modern information technologies.

The introduction of information technologies in industrial production is associated with positive and negative aspects. Initially, financial resources, training, infrastructural changes, and sometimes even layoffs, recruitment or retraining of staff are needed. On the other hand, remote control, improved security and accountability, traceability of the information flow, etc. could be achieved by using them.

Firstly, the implementation of DLT implies security in data transmission, which will first increase trust among partners and therefore improve the working atmosphere. Secondly, it will contribute to the efficient consumption of fuels and resources, which will have an economic effect. Thirdly, the automatic sending and archiving of reports increases the accountability and traceability of all documents to the point of impossibility of theft by third parties.

Naturally, each new technology is built on the basis of a previous one. For example, when upgrading databases with DLT, it was found that the information could be compared and evaluated. On the other hand, data are shared among nodes more slowly compared to the SCADA system, which is designed to manage production processes. The advantage of DLT is the security, nonmodifiability and traceability of the transmitted data, which makes it a suitable system not for managing production processes, but for sharing confidential data among commercial, production and regulatory organizations. With the implementation of this new information technology, different communication channels appear among subjects which exchange data of mutual interest.
Therefore, to assess production support measures according to the criteria of sustainable development, DLT is suitable for sharing information flows in mining enterprises. These are electricity, production, waste, transport, security. As a new technology, whose legislation is from 2019, it is necessary to develop an algorithm for implementation, definition of information channels and definition of the attributes in the blockchain for the described sharing channels. At present, such do not exist yet.

The purpose of this article is to determine the stages of the method for implementing DLT and achieving improved communication by clearly defining the communication channels and the type of transmitted information for the transport sector in a mining enterprise.

\section{Methods}

As a new information technology, the regulations for blockchain and DLT are respectively from 2017 and 2019, which necessitates a brief definition of their functions, advantages and disadvantages. The methods for building DLT are based on different platforms Ethereum, Hyperledger Fabric, Corda and others. These platforms differ according to the method of data transmission, the rights of the participants to modify the data, the transmission speed, etc.

Given the history of DLT, the main research and development of the above-mentioned platforms are for cryptocurrency management [13,14], trade and economic flows, as well as their protection against cyberattacks [15]. In recent years, there has been a study on the implementation of the technology in ticket sales in rail transport [16] and fleet management.

With the isolation due to the COVID-19 pandemic, the real applications of the technology are increasing. The already implemented and working solutions prove the possibilities for tracking cryptocurrencies to various commercial products. Although the DLT regulation is from 2019, there are already successful commercial applications such as tracking the origin of eggs from Farmers Hen House via QR shared codes, authentication of COS sweaters via My Story ${ }^{\mathrm{TM}}$ labels by H\&M and VeChain [17, 18]. The most visible effect is to the transparent and unmodifiable tracking of supplies of medicines and food, encompassing the companies Deloitte, Maersk, the World Bank and the World Food Program [19].

In the industry, as a representative of the transport sector, Volkswagen has implemented DLT to track parts and origins of materials for the manufacture of batteries for electric vehicles [20], management and settings of cars in the construction of smart cities [21]. An analysis of the platforms shows that the Hyperledger Fabric is preferred in the transport sector, as can be seen from the website [22].

At a round table in Toronto, leading IT and mining experts have identified the following streams as leading directions for the implementation of DLT in the mining industry [23]: 
1. Management of the financial resources in communication with banks and suppliers;

2. Communication with state institutions;

3. Human resources management;

4. Repair system when reporting accidents.

The management of vehicle traffic is not explicitly mentioned, but haulage is a major activity in large and distributed mining companies and area 4 - the repair and accident system is part of it. For this reason, the article is aimed at defining the channels of the transport information flow and the shared data.

In order to define the stages for implementing a blockchain-based DLT for transport channels for sharing, these concepts have to be defined first.

Since the organizational structure of each enterprise is the framework for reporting the relationships in an organization, the first step of the proposed methodology is to consider the main organizational structures. The values for measurement and transmission to the respective actors are determined according to the structure of the organization and with regard to the selected information flow. The number of channels for the respective information flow is then determined, as not all data are transmitted to all participants in a given communication scheme.

In order to achieve consensus, decentralization and equality in data transmission, it is necessary to define a consensus mechanism. The following is a design for smart contracts to set sharing rules and a platform selection.

\section{DLT and Blockchain}

DLT is a decentralized database containing information visible to all actors in real time. The system allows the sharing of the necessary information among the network's participants through the respective synchronization. To achieve security, the data is encrypted and changes by each participant are authenticated with their own key. On different platforms, participants' rights to modify the data may be different, but the common denominator is that once modified, the data cannot be deleted. Thus, the system ensures unmodifiability, traceability and transparency of information flows [24].

The blockchain [25], as the name suggests, is a chain of blocks (codes) connected by cryptographic algorithms, containing identical information. The management of transactions in the network is through a consensus mechanism that validates the allowed transactions when adding them to a block. This is a method of authenticating and validating a value or transaction without the need for explicit trust or reliance on a central institution, i.e. on a third party. Thus, the recommendation for economic optimization of expenditures according to the criteria for sustainable development is implemented by eliminating the need for an intermediary and giving the possibility to each participant to be both a provider and a user of data.

The transmission and recording of the information among these participants in the blocks takes place after its verification as genuine through the so-called smart contracts.
The choice of blockchain, smart contract and consensus mechanism depends on the parameters of the organizational structure, the rights of the participants to modify the transactions, the number of information flow channels and the type of information flow.

It has been established in previous studies that the information flows in the mining industry are the supply and reporting of fuel or repair equipment, the monitoring of energy parameters by shifts and departments, the quantity and quality of the extracted or processed product, the monitoring of emissions [26]. These information flows include data from the measures and laws introduced in recent years to reduce harmful emissions, optimize production, introduce new technologies for extraction and transport.

The development of information technologies has necessitated a remote or GPS system for tracking the routes of vehicles. In addition, methods are being developed to study their technical serviceability or efficiency. To carry out the above-mentioned activities, specialized information management is required [27]. In order to improve the efficiency of vehicle management in a mining company through DLT, the transport sector will be analyzed. Due to the differences in mining companies, the options are many and specific, but the information flow in all cases depends on the organizational structure of the company, which requires a brief overview of the main structures.

\section{Organizational structure}

Different organizational structures are characteristic for the mining industry and they depend on the functional peculiarities of production, the history of the organization, and the geographical features. Since mining production includes various activities such as extraction, processing, reclamation, there are different types of companies - Ltd., JSC, holding, industrial group and outsourcing. All these companies are characterized by a hybrid type of organization, which combines functional and geographical type of structure.

\subsection{Holding}

The holding company is a business entity that combines the assets of various subsidiaries and performs supervisory functions. It is characteristic that it generally does not carry out specific business activities and does not actively participate in the management of the day-to-day operations of its subsidiaries. Therefore, this type is not considered in the present study.

\subsection{Industrial group}

The industrial group includes companies that can work in various fields - construction, consulting, mining, energy, environment, haulage, security, etc. The companies in the industrial group can interact among themselves, but they can also have projects with external companies and partners. 


\subsection{Outsourcing}

Outsourcing is the business practice of hiring a firm outside the company to provide services or create goods that are traditionally done internally by the company's own employees and staff. It was first recognized as a business strategy in 1989. This way of transferring tasks is undertaken as a cost reduction measure. This is a method for companies to allocate resources where they are most efficient, according to the criteria for sustainable development. It helps to preserve the nature of free market economies worldwide. This way of transferring tasks allows the companies to focus on key aspects of the business, allocating less critical operations to external organizations.

In the present study, the communication channels in a given outsourcing company are defined, because in the communication among companies it is possible to reduce the security in data transmission, to lose trust among the partners. Therefore, a need for protection arises when transmitting confidential data without disrupting the communication among the suppliers and the company, etc. The implementation of DLT will further facilitate the efforts of the legal teams of the companies when signing contracts in which the type and the way of sharing confidential data must be precisely mentioned.

With the implementation of Internet technologies, in all companies, amorphous parts of the structure have emerged, which can lead to confusion in the management and executive staff. This further reaffirms the need for a DLT, which will clearly define the ways in which the information required is transmitted to each participant.

The object of analysis is the transport information flow, as the communication channels proposed in the article can be modified according to the parameters and organizational features of a specific production process. They can also be used by smaller companies.

\section{Main parameters}

The implementation of each database as well as DLT begins with defining the transmission data [28]. For a transport company working in the mining sector, it is necessary to differentiate the data according to the actors involved.

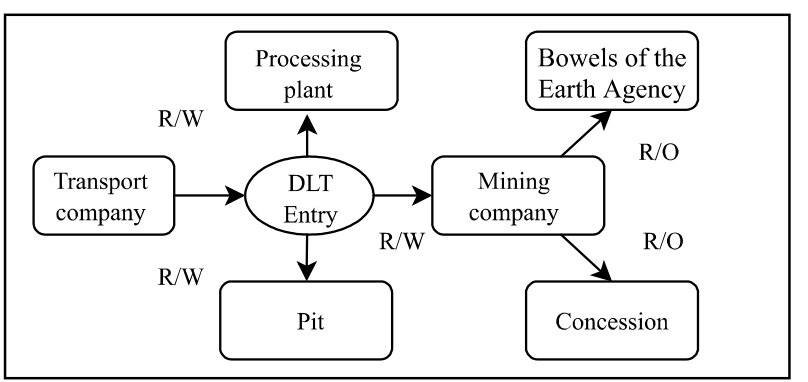

Fig. 1. Scheme of production.

The actors interested in these data are the Pit, the Processing Plant, the Transport Company, the Mining Company. It communicates and shares data with state- owned companies, agencies and regulatory bodies in accordance with the legislation. It is obvious that there are many participants and sharing all the information would complicate the work of each of them. Therefore, the following information flows are defined for the transport sector:

1. The amount of ore. In this information flow among the participating companies are shared data on the parameters: amount of development, amount of ore transported, number of courses of vehicles, fuel consumed, stope (working face). The actors interested in these data are the Pit, the Processing plant, the Transport Company, the Mining Company. They all share the measured values and confirm the received records. The mining company sends official reports to the Bowels of the Earth Agency and the concession, which only accept these data, i.e. their rights are read-only. The conceptual model for communication in this case is visualized in Fig.1.

2. Technical condition. The technical condition of the vehicles of the transport company depends on the working hours, the number of courses of full vehicles, the number of courses of empty vehicles, the distance traveled. In the presence of electric vehicles, the company may have implemented a system for remote diagnostics according to the temperature of certain parts or other parameters. In order to reduce carbon emissions [11], the share of electric vehicles in all sectors of production is expected to increase [29], and the information flow can be supplemented with parameters such as tire condition, battery condition, battery voltage of the individual vehicles, charging time, number of charging cycles, LCC, management or optimization of PV renewable source for charging [30] and etc. Information flows in the management of electric vehicles are not discussed in the article. The data about the technical condition are transmitted by the transport company to the repair company and to the mining company. The conceptual model for communication in this case is visualized in Fig. 2.

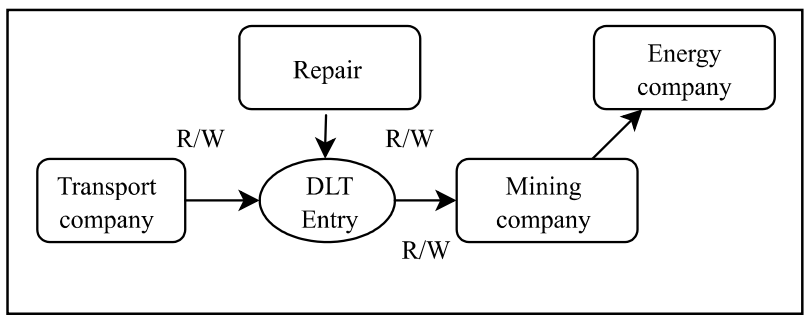

Fig. 2. Scheme of repair flow.

3. Delivery of repair equipment and parts. Every company has repair parts in stock, but each repair is also related to the delivery of new ones. In this information flow, the main data are the number and type of parts in stock and the number and type of parts to be ordered. Therefore, when registering a repair event, the transport company contacts the repair company and the mining company. For its part, the repair company contacts all the 
suppliers. It has information about the technical condition of the fleet and can pre-order the elements necessary for maintenance. The conceptual model for communication in this case is visualized in Fig. 3.

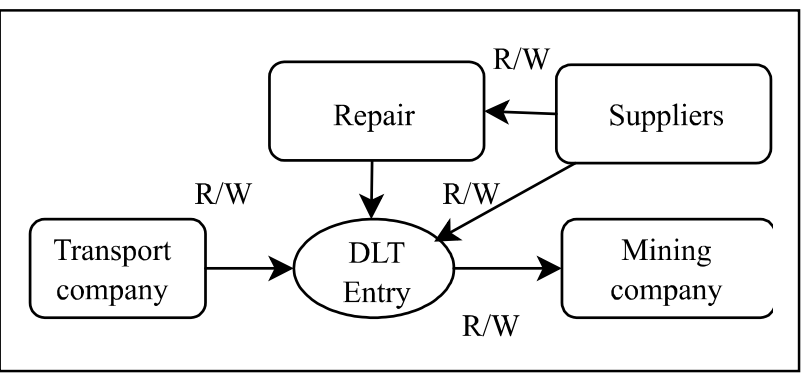

Fig. 3. Scheme of suppliers.

4. Financial flow. The transport company has employees and a fleet. It pays salaries, insurances, trainings to the employees, and buys fuel and energy for the fleet, takes over the repairs. The conceptual model for communication in this case is visualized in Fig. 4.

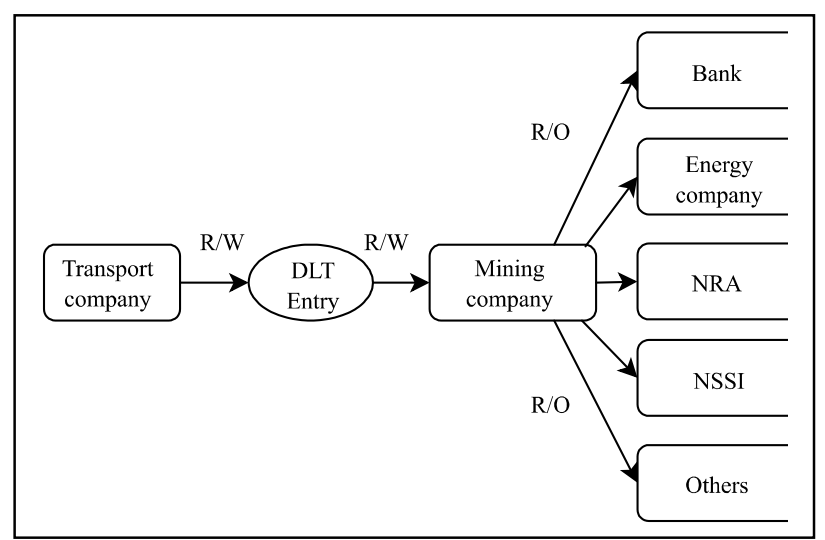

Fig. 4. Scheme of finance flow.

In Figure 4, The Mining company submits data to all external organizations, and they only have the right to view it.

The funds for the financial servicing of the fleet and the employees are received by the Mining Company after reporting on the work performed. In addition, the Transport Company submits a report about its expenditures to the Mining company, which is in contact with the government agencies (National Revenue Agency (NRA), National Social Security Institute (NSSI)), the electricity distribution company and the regulatory authorities.

The only organization that can verify the information sent is the electricity distribution company. This happens when monitoring the parameters of electricity, for example if the transport company has a large number of electric vehicles, which is not reported in the scheme. If it is necessary to halt the activity of the mining company, which is a big consumer of electricity, it warns the electricity distribution company. The same process is repeated at start-up, with the electricity distribution company allowing the start-up of a mining company's activity. If it is necessary to monitor the parameters of electricity, it is necessary to make a separate scheme of information flow related to the quality of electricity, which is among the future tasks of our team.

The study is useful for the mining industry, but the defined flows can be applied to trace hazardous substances in the chemical and pharmaceutical industries, hospitals [4], automotive [20], engineering, agriculture, etc. The results of the study can be applied in other activities after the identification of the following flows:

Characteristics - composition of the flow, source, purification (treatment), discharge - qualitative and quantitative composition, time;

The Supply chain - spare parts, fuel and lubricants quantity, supplier, quality etc.;

Maintenance - regular vehicle checks, distance travel, tracking of the lifetime engineering cycle;

Documents flow - tamper resistance, redundancy, non-repudiation, tracking etc.;

Operational data - drivers working shifts, quantity of raw material transported, regular vehicle position checks.

\section{Consensus mechanism}

The data from the defined information flows are validated when added to a block and transmitted to the network of ledgers by a consensus mechanism. It is not necessary for all participants to see all the information in this structure, which is one of the main criteria for choosing a consensus mechanism. In the event of a software issue or another problem in one of the communication channels, it is necessary for the system to continue to operate, without requiring high speed data sharing.

Analyzing all these features for the case under consideration, the suitable consensus mechanism is the Practical Byzantine Fault Tolerant, in which the management is centralized and carried out by the Mining Company. This mechanism allows a clear definition of the participants without excluding the addition of new ones, for example when signing a contract with a new supplier. It provides protection against Byzantine faults [31]. Although Hyperledger Fabric (v 2.2) ordering service is still not ready with PBFT implementation (RAFT CFT is used), it is marked as the milestone for next releases [32, 33]. In addition, its advantages are that there are no initiatives on the nodes, there is no requirement of hash power.

\section{Smart contracts}

The business logic of the channel is implemented by Smart Contracts, which are computer programs or frameworks that automatically take over tasks and responsibilities in the shared ledger. This is a computer code that recreates the contractual logic of the real world. Acting at the node level under a specific regulation among the participants and the proper functioning of the principle of consensus, they validate and record the shared data. Examples of such platforms are Ethereum, Hyperledger Fabric, etc. The following table 1 provides a comparative analysis of the main platforms. 


\subsection{Ethereum}

Ethereum uses the Proof-of-Work consensus algorithm, in which all participants must reach a consensus on the order of transactions. It lacks confidentiality because any user can see any type of information, which is inapplicable in this case.

Table 1. Comparative analysis of the main platforms

\begin{tabular}{|l|l|l|l|l|}
\hline $\begin{array}{l}\text { DLT } \\
\text { platform }\end{array}$ & Type & $\begin{array}{l}\text { Block } \\
\text { creation } \\
\text { time }\end{array}$ & $\begin{array}{l}\text { Energy } \\
\text { consumptio } \\
\text { n }\end{array}$ & Consensus \\
\hline Bitcoin & public & $10 \mathrm{~min}$. & high & PoW \\
\hline Ethereum & public & $15 \mathrm{sec}$ & high & PoW \\
\hline EOS & public & $0,5 \mathrm{sec}$ & no data & DPoS \\
\hline Cardano & public & $20 \mathrm{sec}$ & no data & Ouroboros \\
\hline Fabric & private & $0,5-2 \mathrm{sec}$ & very low & Modular \\
\hline Sawtooth & private & no data & very low & $\begin{array}{l}\text { PoET } \\
\text { SGX) }\end{array}$ \\
\hline IOTA & private & settings & very low & Tangle \\
\hline Multichain & private & settings & very low & $\begin{array}{l}\text { Distributed } \\
\text { consensus }\end{array}$ \\
\hline Corda & private & $0,5-2$ sec & very low & Notary nodes \\
\hline $\begin{array}{l}\text { Walton- } \\
\text { chain }\end{array}$ & $\begin{array}{l}\text { public and } \\
\text { private }\end{array}$ & $30 \mathrm{sec}$ & low & WPoC \\
\hline
\end{tabular}

\subsection{Corda (R3 CEV)}

Corda was created for financial institutions, with participants agreeing in advance on a set of rules. The Node-to-Node (N2N) consensus algorithm is used, which allows control over the access to the network records. It is suitable in case of a request of a regulator to make a detailed and comprehensive check of the transactions in the network. Achieving security and indisputability of the records is related to the requirement for all participants to be online. For the mining sector, the use of a consensus mechanism suitable for the banking sector is inappropriate.

\subsection{Hyperledger Fabric}

It is designed for corporate use and all peers maintain one ledger for the channel to which they are subscribed (channels can be more than one). However, unlike other blockchains, in Hyperledger Fabric not all nodes are the same and this arises as a result of the different roles of the representatives of the organizations in the network, which is appropriate for the considered information flow - fleet management.

Hyperledger Fabric allows each network member to identify its representatives, which are configured in appropriate cryptographic materials, such as a Certificate of Identity. There is an opportunity to enter individual settings and preferences when building solutions for shared ledgers, which allows multi-channel communication of the transport company when sharing essentially different information flows.

The main shortcoming which is documented is the requirement to develop a list of participants in the network and give them access through membership of a centralized institution. In this case, however, this is an advantage because it coincides with the peculiarities of the considered organizational structure of an outsourcing mining company. Therefore, for the analyzed information flow, this has already been done and Hyperledger Fabric is the appropriate platform. The constraints of the research are the usage of non-permissive DLT platform Hyperledger Fabric in the management of the information flow in a transport company in the mining industry.

The implementation of DLT to the mining industry is an even more controversial issue. We were unable to find research papers on the application of DLT in the mining industry. Examining the maturity of technology, there is a rapid development of the legislative and regulatory framework, as well as the number of companies that have implemented the system. However, this involves costs, organizational changes, staff training, an increased attack area and the need for new cyber defense methods [15]. Despite Deloitte's estimates that by 2025 , about $10 \%$ of global GDP will be based on blockchain structures [34], categories of standards applicable to the DLT and the blockchain have not been developed yet. These are framework standards, technology standards, platformspecific standards and industry-specific standards. The above-mentioned shortcomings are typical not only for DLT, but also for most information systems for data transmission.

Despite these limitations in the implementation of DLT as an ever-changing legal framework, the high electricity costs for data transactions, the need for staff training and more, the team believes that applications will increase worldwide. According to [35] DBMS should provide:

- Data storage, retrieval and update;

- User accessible catalog or data dictionary describing the metadata;

- Support for transactions and concurrency;

- Facilities for recovering the database, should it become damaged;

- Support for authorization of access and update of data;

- Access support from remote locations;

- Enforcing constraints to ensure data in the database abides by certain rules.

Thus, data confidentiality, processing logic, irreversibility, non-repudiation, and data redundancy aren't any part from an initial DBMS fully fledged solution. However, they can be partially achieved with additional explicitly added IT procedures which are out of scope of our research. DLT solutions implicitly add an additional layer that provides the described missing properties on the top of the DBMS solution.

\section{Conclusions}

According to the criteria for sustainable development in the mining sector, fleet management through a new information technology has been proposed. The article presents an algorithm for implementing DLT in an outsourcing company for sharing data by a transport company.

According to the methodology, the directions for sustainable development of the mining sector were 
initially clarified and the peculiarities of the organizational structure of an outsourcing mining company were analyzed. In order to build information management, it is necessary to define variables for data sharing for a transport company and a description of the main information flows. Conceptual models of the main information flows are proposed. The variables in the described information flows are not final and depending on specific features of each mining company, changes in the regulatory requirements and in the activity can be made or new ones can be added.

Based on the participants in the communication channels, the presence of a centralized management organization, the required level of security and data transfer speed, the consensus mechanism Practical Byzantine Fault Tolerant was chosen. It ensures continuous operation, even in the presence of a software problem and the ability to add new participants.

A platform for regulating the contractual data sharing policy has been chosen. Hyperledger Fabric was chosen because it is the closest to the considered organizational structure which needs multi-channel data sharing. The suggested solution provides a fast transaction finality time - e.g. in Hyperledger Fabric it varies from $150-200 \mathrm{~ms}$ to $2 \mathrm{sec}$. Exposition of new attack vectors, thanks to increased attack surface. This platform is suitable not only for the transport sector in a mining company, but also for the transport sector as a whole. In addition, Hyperledger Fabric is suitable for other information flows in the mining industry - tracking of resources, electricity, etc.

New perspectives for further research are the classification of the data passed to the DLT system and maintenance of the DLT system.. The attributes of the block are not determined for the defined information flows of the transport company for an outsourcing company, this will be among the future tasks of the team.

This research was supported by the Bulgarian projects under contract: "Study of the possibilities for application of DLT using blockchain in data sharing in mining activities and electricity production from biogas "MEMF-164".

\section{References}

1. J. Dubiński, J. Sust. Min, 12, 6 (2013)

2. Report of the World Commission on Environment and Development: Our Common Future, (WCED, 1987), p. 300

3. M. Fischedick, J. Roy, Industry, ed. by R. Clift, V. Nenov, (Cambridge University Press, USA, 10, 2018)

4. N. Khan, S. Khan, S. Ahmed, I. Farooqi, S. Vambol, V. Vambol, Smart ways of hospital wastewater management, regulatory standards and conventional treatment techniques, HWM, (2019), doi: DOI 10.1108/SASBE-06-2019-0079

5. B. Vladkova, T. Bakardjieva T. (ed), Tehnicheska bezopasnost (Technical Safety), (Publishing house "St. Ivan Rilski, Sofia, 2020)

6. O. Kruzhilko, O. Polukarov, S. Vambol, V. Vambol, N. Khan, V. Maystrenko. V. Kalinchyk, A. Khan,
Control of the workplace environment by physical factors and SMART monitoring, Archives of MScE, 1, 103, 18-29, (2020), doi: $10.5604 / 01.3001 .0014 .1770$

7. J. Segura-Salazar, L. M. Tavares, Sustainability in the Minerals Industry: Seeking a Consensus on Its Meaning, Sust., 10, 5, p. 38 (2018), doi: $10.3390 /$ su10051429

8. Directive 2006/21 / EU on the management of waste from extractive industries and amending, 2006

9. I. Koprev, K. Karadjova, V. Paneva, ed. by P. Bokov, G. Min. Res, Management of mining wastes, 10, 4 (2008)

10. B. Galabova, B. Trifonova, Innovative practices in the management of a mining company, Paper presented at the 61rd international conference of the University of Mining and Geology "St. Ivan Rilski, Sofia, 19-20 Oct 2018

11. V. Petrova, D. Kostova, V. Velev, Corporative social responsibility - factor for sustainable development,. Paper presented at the 55rd international conference of the University of Mining and Geology "St. Ivan Rilski, Sofia, 20-21 Oct 2012

12. P. Lesagel, C. Reid, M. Margni, M. Aubertin, L. Deschênes, Use of LCA in the mining industry and research challenges, Paper presented at the Symposium sur l'environnement et les mines, Jan 2008

13. S. Nakamoto, Bitcoin: A Peer-to-Peer Electronic Cash System (2008), www.bitcoin.org, Accessed Nov 2020

14. S. Nakamoto, Bitcoin: A Peer-to-Peer Electronic Cash System,Manubot, (Tech. Rep., 2019)

15. W. Dimitrov, R. Silhavy, R. (ed.), The Impact of the Advanced Technologies over the Cyber Attacks Surface Artificial Intelligence and Bioinspired Computational Methods, (Springer International Publishing, 10, 2020, In Proceedings)

16. D. Preece, J. M. Easton, IEEE Int. Conf. Big Data (Big Data), 7, (2019)

17. Transparency on the Farm, F. H. H. https://www.farmershenhouse.com/free-range-eggs, Accessed 23 Nov 2020

18. J. Rodríguez, H\&M to Use Blockchain to Trace its Products, IHODL. https://ihodl.com/topnews/202004-27/hm-use-blockchain-trace-products. Accessed 23 Nov 2020

19. M. Linnet, S. Wagner, H. Haswell, Maersk and IBM Introduce Trade Lens Blockchain Shipping Solution (9 Aug 2018), https://newsroom.ibm.com/2018-0809-Maersk-and-IBM-Introduce-TradeLensBlockchain-Shipping-Solution. Accessed 25 Nov 2020

20. Br. McCreahttps, Volkswagen uses blockchain for automotive supply chain: Page 3 of 3 (3 May 2019), eenewspower.com, www.eenewspower.com/news/volkswagen-uses- 
blockchain-automotive-supply-chain, Accessed 25 Nov 2020

21. A. Zero, Blockchain and Automotive Industry. Where Are They Heading? (21 Aug 2019), https://alephzero.org/blog/blockchain-automotiveindustry. Accessed 25 Nov 2020

22. Hyperledger, members, https://www.hyperledger.org/about/members. Accessed 1 Mart 2021

23. White paper, Blockchain Understanding the practical applications for mining (2019), MJI Infosys, https://www.infosys.com/industries/mining/Docume nts/practical-applications-mining.pdf. Accessed 25 Nov 2020

24. Procedure completed 2017/2772(RSP), Distributed ledger technologies and blockchains: building trust with disintermediation, 2017

25. Procedure 2018/2085(INI), Blockchain: a forwardlooking trade policy, 2018

26. T. Hristova, Blockchain application in mining management, E3S Web of Conf. RGMET, 168, 0009, (2020), doi.org/10.1051/e3sconf/202016800009

27. Yo. Anastasova, N. Yanev, I. Vecherkov, Possible application of Business Intelligent in the Mining Industry, Paper presented at the 7th Balkan Mining Congress BALKANMINE, in Prijedor Republic of Srpska, Bosnia and Herzegovina, 11-13 October 2017

28. N. Yanev (ed), Metodologii I technologii za razrabotvane na informatsionni sistemi (Methodologies and technologies for development of information systems), (Publishing house "St. Ivan Rilski, 2013)

29. I. Beloev, K. Gabrovska-Evstatieva, B. Evstatiev, Compensation of $\mathrm{CO}_{2}$ Emissions from Petrol Stations with Photovoltaic Parks: Cost-Benefit and Risk Analysis, Acta Tech. Agricult., 20 (4), 85-90, (2017).doi: https://doi.org/10.1515/ata-2017-0017

30. Ts. Varbov, G. Velev, Optimization of the Inter-Row Spacing for Ground Mounted PV Systems for Increasing the Annual Production of Electric Energy Using PVGIS-CMSAF, Paper presented at the BULCAMC, Sofia, 19-20 November 2020

31. L. Lamport, R. Shostak, P. Marshall, ACM, TOPLAS 4, 3, (1982)

32. M. Castro, B. Liskov, Practical byzantine fault tolerance, Paper presented at the Third Symposium on Operating Systems Design and Implementation, New Orleans, 1999

33. D. Ongaro, J. Ousterhout, RAFT: In Search of an Understandable Consensus Algorithm (Extended version), (Stanford University, 2015)

34. Deloitte (2 Sept 2017), https://www.freightwaves.com/news/2017/9/2/deloit te, Accessed 23 Nov 2020

35. T. Connolly, C. Begg, Database Systems - A Practical Approach to Design Implementation and Management, (Pearson, 2014) 